Volumen $14 \mathbf{n}^{\circ} 42011$

\title{
Editorial
}

\section{1: CRISIS ECONÓMICA Y METAS PENDIENTES PARA LA ENFERMERÍA ESPAÑOLA}

El año 2011 no pasará desapercibido para nadie, pues nos deja una gran crisis económica y su repercusión en forma de recortes en la sanidad; recortes que en ocasiones están teniendo una incidencia directa en la contratación de enfermeras, más o menos evidente en la mayoría de Comunidades Autónomas (CCAA). En otros casos no se trata de recortar contratación, pues ya se venía realizando en algunas de ellas, sino aumento de las ratios pacientes/enfermera, que viene a ser lo mismo. Desde el punto de vista de los gestores sanitarios, teniendo en cuenta la grave crisis económica en la que está inmerso nuestro país, están justificadas todas las medidas de ahorro que supongan racionalizar el gasto sin recortar prestaciones al ciudadano. No obstante, hay que recordar a estos gestores que España tiene un promedio de 4.9 enfermeras por cada 1000 habitantes, bastante por debajo del promedio de la Organización para la Cooperación y el Desarrollo Económico (OCDE) que es de 8.4, según los datos del Informe sobre la salud 2011, publicado recientemente por esta organización ${ }^{1}$. Sin embargo, el gasto sanitario de 2009, como proporción del Producto Interior Bruto (PIB) alcanzó el $9.5 \%$ en nuestro país, igual al promedio de los países de la OCDE. Es decir, gastamos en salud la misma proporción de PIB que la media de estos países, pero con una proporción de enfermeras, de casi la mitad con respecto a los mismos. Por tanto, si es que existe alguna desviación en el gasto sanitario en nuestro país que hay que corregir, no estaría justificado que el recorte afectara a las plantillas de enfermeras, al menos en la mayoría de CCAA. Muy al contrario, sería deseable que las distintas administraciones sanitarias intentaran corregir este déficit de enfermeras para estar en los mismos indicadores sanitarios que la mayoría de los países de nuestro entorno, pues el gasto absoluto depende de la riqueza de cada país, pero el relativo (promedios) debería ser muy homogéneo entre los mismos.

Otro aspecto que quisiera destacar, es que en este año que acaba, tampoco se va desarrollar la Especialidad de Enfermero Especialista en Enfermería Médico-Quirúrgica, denominación impuesta en su momento por el Ministerio de Educación, con la excusa de que dicha denominación era la más homologable respecto a otros países, cuando se publicó la Ley de Especialidades de Enfermería en 2005². En aquel momento, la propuesta de denominación del Consejo General de Enfermería y la Federación de Asociaciones Científicas de Enfermería para esta especialidad fue la de Enfermería Clínica Avanzada con diferentes Áreas de Capacitación Específica, cuyas competencias justificaran las mismas, posibilidad esta que contempla la Ley de Ordenación de las Profesiones Sanitarias ${ }^{3}$. Curiosamente un año antes, se había publicado el Libro Blanco Titulo de Grado de Enfermería por la ANECA (junio 2004) y en el capítulo análisis de la situación de los estudios en Europa, vienen recogidas en unas tablas la existencia o no de especialidades de enfermería, y en su caso, la denominación de las mismas, en los diferentes países de Europa con los cuales íbamos a converger en materia de Educación Superior: Alemania, Austria, Bélgica, Dinamarca, Finlandia, Irlanda, Francia, Grecia, Holanda, Italia, Noruega, Suecia, Reino Unido, Suiza, Portugal ${ }^{4}$. Pues bien, en ninguno de ellos excepto en Portugal, existe especialidad alguna con esa denominación, o sea de 15 países analizados, tan solo Portugal tiene una especialidad de Postgrado con dicha denominación. Pero como comentaba anteriormente, desde el Ministerio de Educación se impuso la denominación de una especialidad, que con lo único que tenía correspondencia era con la materia Enfermería Médico-Quirúrgica de los planes de estudios de Diplomado en Enfermería. Ahora ni con eso, pues la denominación Enfermería Médico-Quirúrgica ha desaparecido de todos los planes de estudios del Grado de Enfermería, sustituyéndose por Enfermería Clínica 0 Enfermería del Adulto, y estas sí que son homologables al resto del mundo.

1. http://stats.oecd.org/index.aspx?DataSetCode=HEALTH_STAT (consultado el 20-11-2011).

2. Real Decreto 450/2005, de 22 de Abril sobre Especialidades de Enfermería, publicado el 6 de Mayo.

3. Ley $44 / 2003$ de 21 de noviembre, publicada en el BOE 280, de 22 de noviembre, desarrolla el ejercicio de las profesiones sanitarias (LOPS).

4. http://www.aneca.es/var/media/150360/libroblanco_jun05_enfermeria.pdf (consultado el 20-11-2011).

Rodolfo Crespo Montero

Director de la Revista de la Sociedad Española de Enfermería Nefrológica

El contenido de la revista expresa únicamente la opinión de los autores, que no debe coincidir necesariamente con la de la Sociedad que esta revista representa.

Esta publicación se imprime en papel no ácido. 